\title{
Investigation of the effect of linoleic acid on vascularization in experimentally induce zoledronic acid-related osteonecrosis in rats
}

\author{
Ziya Yurtal ${ }^{1}$, Gözde Serindere ${ }^{2}$, Ceren Aktuna Belgin ${ }^{2}$, Lutfi Takci ${ }^{3}$
}

\author{
${ }^{1}$ Department of Surgery, Faculty of Veterinary Medicine, Hatay Mustafa Kemal University, Hatay/TURKEY \\ ${ }^{2}$ Department of Dentomaxillofacial Radiology, Faculty of Dentistry, Hatay Mustafa Kemal University, Hatay/TURKEY \\ ${ }^{3}$ Department of Anatomy, Faculty of Veterinary Medicine, Sivas Cumhuriyet University, Sivas/TURKEY
}

Key Words:

bisphosphonate

conjugated linoleic acid

osteonecrosis

rat

SEM

Received : : 12.07.2021

Accepted : :01.12.2021

Published Online : 31.12 .2021

Article Code : 970180

Correspondence:

Z YURTAL

(ziyayurtal@gmail.com)

ORCID

Z. YURTAL

G. SERINDERE

0000-0001-6080-1860

C. AKTUNA BELGIN: 0000-0001-7780-3395

0000-0002-8865-8186

\begin{abstract}
Bisphosphonate-related osteonecrosis of the jaw is an increasingly common pathological condition whose pathophysiology is not fully understood and can be difficult to manage. The unique biological effects of conjugated linoleic acid include angiogenic, anticarcinogenic, antiatherosclerotic, antioxidative, immunomodulatory, and antibacterial effects. The aim of this study is to compare the osteonecrosis areas created by tooth extraction with the control group using scanning electron microscopy after the administration of zoledronic acid, conjugated linoleic acid, and a combination of both in the rat jaw. A total of 50 Wistar Albino male rats weighing 400-450 grams were used. The groups were randomly divided into 5 groups: the control group, the sham group, the group that received zoledronic acid, the groups that received conjugated linoleic acid with zoledronic acid $(100 \mathrm{mg} / \mathrm{kg}$ and $200 \mathrm{mg} / \mathrm{kg}$ ), and the study lasted a total of 10 weeks. Regardless of the use of zoledronic acid, it was observed by scanning electron microscopy that vascularization was impaired in all groups with tooth extraction. Neovascularization did not occur in the groups where conjugated linoleic acid was applied, regardless of the dose. It was concluded that scanning electron microscopy analysis and corrosion casts technique can be considered as an alternative method in such studies due to its accessibility and low cost in observing dental vascularization. However, no definite conclusion could be reached about the neovascularization efficiency of conjugated linoleic acid within the period evaluated after tooth extraction.
\end{abstract}

\section{INTRODUCTION}

Bisphosphonates are antiresorptive drugs (1). It has been used for over 40 years to treat different diseases with increased bone resorption, such as osteolytic bone metastases, Paget's disease, hypercalcemia, primary and secondary hyperparathyroidism, and osteoporosis (2). Numerous studies have confirmed the relationship of bisphosphonates to decrease the incidence of osteoporosis-related fractures by increasing bone mineral density $(3,4)$.

It has been reported that the incidence of bisphosphonaterelated osteonecrosis of the jaw (BRONJ) ranges from 1\% to $10 \%$ in patients receiving intravenous bisphosphonate therapy $(5,6)$. It has been reported that BRONJ is more prevalent in the mandible $(70 \%)$ than in the maxilla (30\%) (7). Trauma to the bone, which occurs especially after tooth extraction, has been reported to be a triggering factor and is found in most cases $(7-10)$.

Due to the antiangiogenic effect of bisphosphonates, impairment in jaw bone vascularization may be observed $(11,12)$. As another reason, it has been reported that there may be direct toxicity of bisphosphonates for epithelial cells with reduced microcirculation of the gum (13).

Conjugated linoleic acid (CLA) is a mixture of conjugated positional and geometric isomers of linoleic acid (cis-9, cis-12 octadecadienoic acid). CLA has 18 carbon atoms. It contains two double bonds and these double bonds are listed as different isomers from different cis-trans configurations at the 9th and 10 th, 11th and 12th or 11th and 13th positions in the carbon chain (14). The proteins, including oleic acid, cholesterol, and linoleic acid, vascular endothelial growth factor (VEGF), angiopoietin, angiotensin, and erythropoietin, are natural molecules required for the initial stage of angiogenesis in vascular maturation (15).

The aim of this study was to investigate the effects of CLA on vascularization in ZA-associated osteonecrosis of the rat jaw using scanning electron microscopy (SEM).

\section{MATERIAL and METHODS}

This study was approved by the Local Ethics Committee for Animal Care of the Hatay Mustafa Kemal University (10/09/2019- decision number: 2019/ 07-2). Fifty Wistar Albino male rats weighing 400-450 grams were used in the study. The rats were housed at a room temperature of $22 \pm 2$ ${ }^{\circ} \mathrm{C}, 12$ hours a night, 12 hours a day. Before starting the experiments, the animals were adapted to the environment for 2 weeks, food, water and ad libitum were given.

Rats were divided into 5 groups: 
1st group- control group: The rats in the control group were not treated and housed under the same conditions as the other experimental groups.

2nd group- sham group: ZA and CLA were not given to the rats in the sham group. Only the right molar teeth were extracted at the 4th week and were sacrificed in the 10th week.

3rd group- ZA group: Rats in this group were intraperitoneally (16) injected ZA (Ronidro $5 \mathrm{mg} / 100 \mathrm{ml}$, and Pharmaceuticals, Turkey) at a dose of $100 \mu \mathrm{g} / \mathrm{kg}$ once a week for 8 weeks (17). The right molar teeth were extracted in the 4 th week and were sacrificed at the 10th week.

4th group- ZA + CLA group (100 mg/kg): Rats in this group were intraperitoneally injected ZA at a dose of $100 \mu \mathrm{g} /$ $\mathrm{kg}$ once a week for 8 weeks, CLA (Linoleic acid 99\%, CAS RN: 60-33-3, Acros Organics, Sweden) was administered by oral gavage at a dose of $100 \mathrm{mg} / \mathrm{kg}$ every day (18). Extraction of the right molar teeth was performed at the 4th week and sacrificed at the 10 th week.

5th group- ZA + CLA group (200 mg/kg): Rats in this group were intraperitoneally injected ZA at a dose of $100 \mu \mathrm{g} /$ $\mathrm{kg}$ once a week for 8 weeks, while CLA was administered daily at a dose of $200 \mathrm{mg} / \mathrm{kg}$ via oral gavage. The right molar teeth were extracted at the 4th week and were sacrificed at the 10th week.

Experimental animals in tooth extraction applications, xylazine $\mathrm{HCl}(10 \mathrm{mg} / \mathrm{kg}$ ) (Alfazine 2\%, Egevet, Turkey), ketamine $\mathrm{HCl}(50 \mathrm{mg} / \mathrm{kg}$ ) (Alfamine, 10\% Egevet, Turkey) were performed with combinations. Extraction was performed on the right mandibular molar teeth by using a molar luxation and a molar extractor.

In this study, the corrosion casts technique was used to evaluate the vascularization of the mandible in sacrificed rats. Phosphate Buffer Salin (PBS) solution was given to clean the blood through a 26 Gauge purple catheter placed in the right common carotid artery and left common carotid artery of the rats dissected using appropriate methods (Figure 1A). After formaldehyde solution was given for fixation of the vessels (Figure 1B), a mixture of methylmethacrylate prepared in a certain amount was manually injected into the vein under constant pressure $(120 \mathrm{mmHg})$ and at an appropriate perfusion rate (Figure 1C). After the methylmethacrylate injection, the mandibles were kept in hot water at $45-55^{\circ} \mathrm{C}$ for $16-24$ hours to completely polymerize. After polymerization, it was kept in a $50^{\circ} \mathrm{C}$ stove for $2-3$ days in repeated potassium hydroxide $(\mathrm{KOH})$ solutions to dissolve the tissue around the vessels.

\section{RESULTS}

During the study, no complications occurred during the administration of oral gavage and intraperitoneal injection. It was noted that in the rats in groups 2, 3, 4 and 5, where tooth extraction was applied, bleeding occurred during tooth extraction, especially during the extraction of caudal molar teeth. This showed that bleeding control during tooth extraction is important. Following tooth extraction, a total of 3 rats, 1 rat in group 2 and 2 rats in group 4 died from anesthesia. When the castes obtained from the control group were examined by SEM, it was observed that the inferior alveolar artery followed a suitable course for the curvature of the corpus mandible after entering the foramen mandible. During the course, branches separated from this vein for each tooth were detected (Figure 2A). This main branch gave lateral branches to the surrounding tissues before entering the pulp from the tooth root (Figure 2B). The vein caused a ball-like reticulation for vascularization of the dental pulp after entering the tooth root (Figure 2C-D).
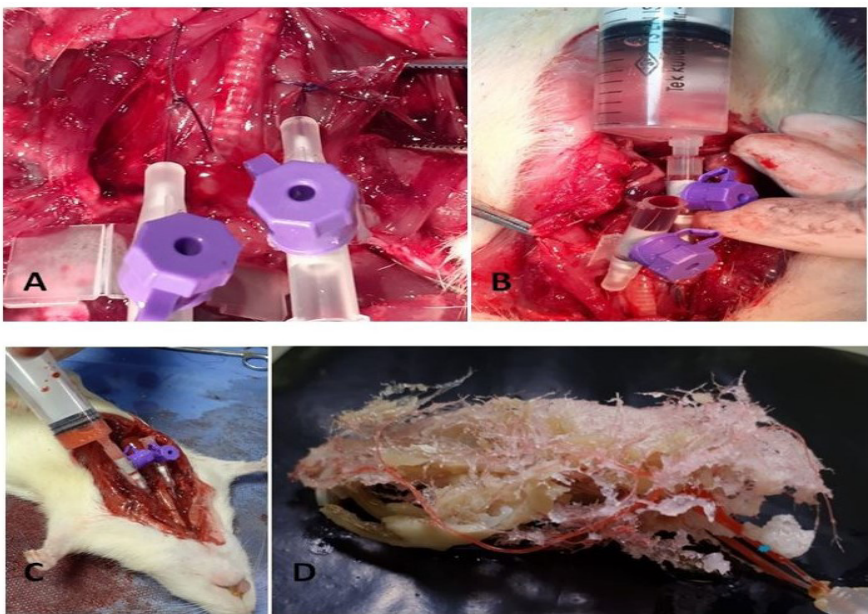

Figure 1. A. Inserting and fixing catheters to the a. carotis communis. B. Fixation of the vessel with formaldehyde solution. C. Administration of methylmethacrylate prepared by manual pressure to a. carotis communis. D. Image of a rat head in the corrosion casts stage. Blue asterisk: a. carotis communis
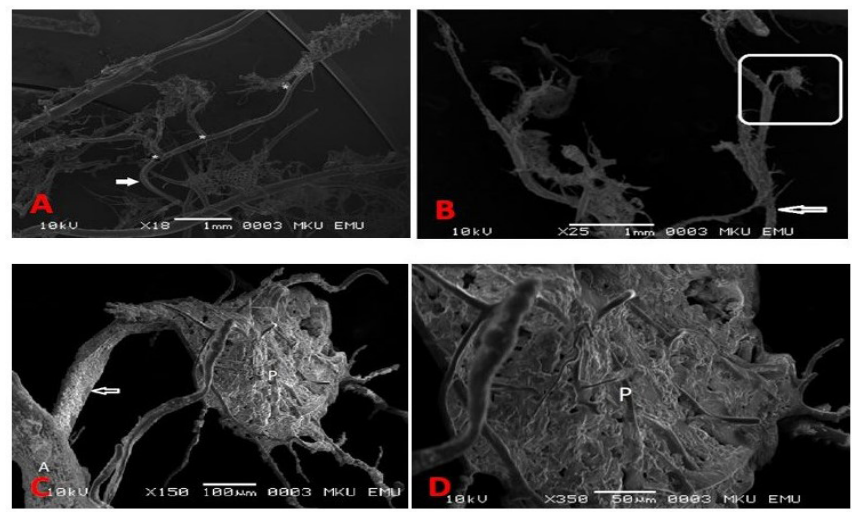

Figure 2. A. Control group, the course of the a. alveolaris inferior after it enters the foramen mandible. Arrow: a. alveolaris inferior. Asterixes: Branches given by a. alveolaris inferior to the tooth roots and surrounding tissues. B. Control group, Arrow: A. alveolaris inferior, Rectangular box: branch of a. alveolaris inferior to the root of the tooth. C. Control group, ball-like vein reticulation in the pulp, A. alveolaris inferior (White A), ball-like reticulation in the pulp $(\mathrm{P})$. Arrow: Branch from the a. alveolaris inferior to the tooth root. D. Control group, high magnification view of ball-like reticulation in the pulp. P: Ball-like reticulation.

Pulpal vascularization was not observed in the SEM images obtained in the other four groups except the control group, as the vascularization of the pulp was impaired due to tooth extraction. Branches given by the inferior alveolar artery to the 
surrounding tissues were determined. The branches that gave to the roots of the teeth ended blindly (Figure 3A).

Ball-like reticulation on the pulp was not seen in the groups that had a tooth extraction. Similar results in the sham group and the other groups in which medication was applied (Figure 3B), showed that tooth extraction impaired vascularization. Vascularization was impaired in all groups that underwent tooth extraction independent of ZA use.

There was no difference in vascularization between the ZA group (3rd group) (Figure 3B-C-D) and the other groups (4th and 5th groups) where different doses of CLA were applied with ZA (Figure 3C-D).

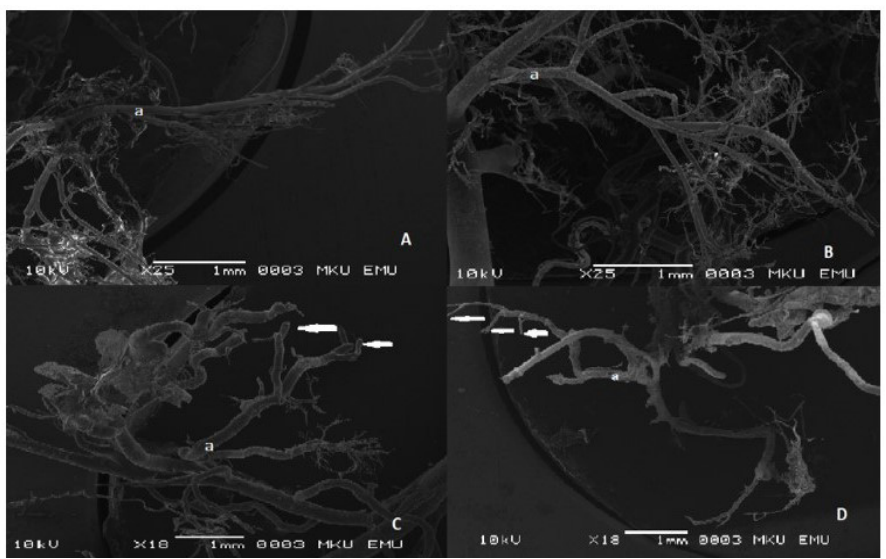

Figure 3. A. A. alveolaris inferior (a) image obtained from Group 2 and whose branches end up blindly to the tooth roots. B. A. alveolaris inferior (a) image obtained from Group 3 and whose branches end in the tooth roots blindly. C. A. alveolaris inferior and blind terminated vessel terminations (arrows) in Group 5. D. A. alveolaris inferior and blind terminated vessel terminations (arrows) in Group 4.

\section{DISCUSSION}

$\mathrm{ZA}$ is the bisphosphonate with the highest potential for osteonecrosis $(10,000$ times higher than etidronate) in the group of amino-bisphosphonates (19). Therefore, it is one of the most commonly used bisphosphonates in animal experimental models, which is more frequently associated with the development of osteonecrosis (20).

The main theories of bisphosphonate-related osteonecrosis are on the suppression of bone remodeling, leading to reduced bone repair in trauma cases such as tooth extraction, mediated by osteoclast damage. It has been reported that one of the possible factors in the pathogenesis of bisphosphonate-related osteonecrosis is vascularization disorders resulting from the antiangiogenic effects of bisphosphonates $(11,12,17)$. In our study, it is in agreement with the results of other studies in the literature $(17,20)$. Vascularization was impaired in the bisphosphonate applied groups in rats.

Based on the study of Kün-Darbois et al. (17), high doses of ZA were used in this study $(100 \mu \mathrm{g} / \mathrm{kg}$ per week for 8 weeks). This dose is equivalent to that used in the clinical treatment of myeloma in humans. (12). It is known that high dose use and long-term treatment significantly increase the chance of developing bisphosphonate-related osteonecrosis lesions (21). Based on the study of Camacho-Alonso et al. (16), the intraperitoneal injection method was used in the present study (16). However, Camacho-Alonso et al. (16) investigated the bone mineral composition upon fracture resistance based on energy-dispersive X-ray spectrometry. In the present study, SEM and corrosion casts technique was used to observe the effect of CLA on vascularization.

In BRONJ, the mandible is affected twice as often as the maxilla and is caused by dental surgical procedures in $60 \%$ of cases $(7,22)$. Therefore, in our study, tooth extraction in the mandible was preferred as a procedure that would lead to the development of bisphosphonates.

Imaging methods such as Magnetic Resonance Imaging (MRI) and Micro-Computed Tomography (Micro-CT) have been used to reveal the changes in the vascularization of the mandible caused by the use of bisphosphonates (17). The corrosion casts technique is also used in many organs and tissues, which is based on creating a copy and analyzing it with SEM to reveal vascularization in three dimensions (23).

In a study conducted in guinea pigs, vascularization of the mandible was demonstrated by SEM using the corrosion caste technique (24). In addition, there are some studies in dentistry where SEM and corrosion cast techniques are used to analyze the vascularization of the enamel organ developing in the molar teeth of rats, the vascularization of the periodontal ligament and tongue dorsum in rats, and the vascularization of the submandibular, sublingual and lymph nodes in rats $(25,26)$. In this study, SEM and corrosion cast techniques were preferred because of their ease of accessibility and low cost compared to other imaging methods.

In SEM analysis, vascularization was impaired in all groups with tooth extraction independent of ZA using, and this showed that osteonecrosis may occur in the extraction of healthy teeth with continued vascularization, independent of the use of ZA. The fact that bisphosphonate-associated osteonecrosis occurs only in the jaws and protects the long bones and an axial skeleton is an important unanswered question. The teeth, oral mucosa, periodontal tissues, muscles, tongue, salivary glands, and alveolar bone that make up the orofacial complex must interact to perform functions such as chewing, speaking, and swallowing (27). The maxilla and mandible are separated by a mucosa from the external environment (28) where bacterial infections such as caries and periodontal disease are common (29). Altered bone remodeling, inhibition of angiogenesis, microtrauma, and bacterial infection have been hypothesized as the cause of vascularization disorder (10). Therefore, in our study, these theories were evaluated as possible causes of vascularization disorder in all tooth extraction groups, regardless of ZA use.

Samson et al. (15) reported that proteins such as oleic acid, cholesterol and linoleic acid, VEGF, angiopoietin, angiotensin, and erythropoietin are natural molecules that constitute the initial stage of angiogenesis in vascular maturation. In another study conducted by Samson et al. (30) in chick embryo, it was reported that new vessel formation accelerated where specific lipids were increased, including chorioallantoic membrane 
analysis of the chick embryo, oleic acid, cholesterol, linoleic acid, and doxahexaeoic acid-lysophosphatidylcholine.

Omega-6 fatty acid metabolites support angiogenesis by increasing growth factor expression (31). Based on this, in our study, we aimed to evaluate the effectiveness of CLA in order to provide neovascularization in necrosis areas caused by bisphosphonate. However, neovascularization did not occur in the groups where CLA was applied, regardless of the dose.

We think that the absence of neovascularization may be due to some reasons. One of them is that although many studies were analyzed in the literature regarding the time required for neovascularization, the 10 -week period may not be sufficient for neovascularization. In the study of Wang et al. (32), osteochondral vascularity in mandibular rat condyles was evaluated histologically at the end of the 20th and 24th weeks according to the age of the rats. However, in the study of Widyastuti et al. (33), it was reported that fibroblast growth factor (FGF-2) and VEGF increased and angiogenesis started on the 7th day following tooth extraction. Luthfi et al. (34) reported that capillary vascularization occurred in the first week. Rowe et al. (35) reported that mandibular distraction osteogenesis was associated with intense vascular response in the early stages. Another point is that the amount of CLA doses may not be sufficient to see its effectiveness. Since there is no literature information about this subject, we believe that using different dose rates in future studies will guide the authors in evaluating the efficiency of CLA.

To the best of our knowledge, this study is the first study in the literature evaluating the efficacy of CLA in eliminating BRONJ. Therefore, we think that the result of this study will be a guide for future studies, while the absence of previous studies about this subject, can be shown as a limitation of this study. In the corrosion casts technique, the inability to control the steps in the preparation stages of the samples, the high risk of artifact formation and the sensitivity to user errors can be considered as the disadvantages of the technique. The main advantages of this technique compared to other imaging methods are that it requires less cost, can show a lot of detail and is easy to access. There are few studies in the literature evaluating dental pathological vascularization. It has been observed that this method can also be an alternative method for imaging pathological vascularization.

\section{CONCLUSION}

Neovascularization did not occur in the groups where CLA was applied, regardless of the dose. Using ZA and CLA for a longer time, giving different doses, using different imaging methods, conducting molecular studies with imaging methods, may be useful for future studies.

\section{DECLARATIONS}

\section{Ethics Approval}

This study was approved by the Local Ethics Committee for Animal Care of the Hatay Mustafa Kemal University (10/09/2019- decision number: 2019/ 07-2).

\section{Conflict of Interest}

The authors declare that they have no competing interests.

\section{Author Contribution}

Idea, concept and design: ZY, GS, CAB, LT

Data collection and analysis: ZY, LT

Drafting of the manuscript: ZY, GS

Critical review: ZY, GS, CAB, LT

\section{Data Availability}

The data that support the findings of this study are available from the corresponding author upon reasonable request.

\section{Acknowledgement}

The authors would like to thank undergraduate students Yusuf $\mathrm{Bal}$ and Özlem Güzey for their support during the feeding of the rats. This study was supported by Hatay Mustafa Kemal University Scientific Research Projects (BAP) (Project No: 19.M.058).

\section{REFERENCES}

1. Rodan GA, Fleisch HA. Bisphosphonates: mechanisms of action. J Clin Invest. 1996;97:2692-6.

2. Lewiecki EM. Safety of long-term bisphosphonate therapy for the management of osteoporosis. Drugs. 2011;71:791814.

3. Harrington JT, Ste-Marie LG, Brandi ML, Civitelli R, Fardellone P, Grauer A, et al. Risedronate rapidly reduces the risk for nonvertebral fractures in women with postmenopausal osteoporosis. Calcif Tissue Int. 2004;74:129-35.

4. Pols HA, Felsenberg D, Hanley DA, Stepán J, Muñoz-Torres M, Wilkin TJ, et al. Multinational, placebo-controlled, randomized trial of the effects of alendronate on bone density and fracture risk in postmenopausal women with low bone mass: results of the FOSIT study. Fosamax International Trial Study Group. Osteoporos Int. 1999;9(5):461-8.

5. Vahtsevanos K, Kyrgidis A, Verrou E, Katodritou E, Triaridis S, Andreadis CG, et al. Longitudinal cohort study of risk factors in cancer patients of bisphosphonate-related osteonecrosis of the jaw. J Clin Oncol. 2009;27(32):5356-62.

6. Walter C, Al-Nawas B, Frickhofen N, GammH, Beck J, Reinsch L, et al. Prevalence of bisphosphonate associated osteonecrosis of the jaws in multiple myeloma patients. Head Face Med. 2010;6:11.

7. Woo SB, Hellstein JW, Kalmar JR. Narrative [corrected] review: bisphosphonates and osteonecrosis of the jaws. Ann Intern Med. 2006;144:753-61.

8. Ruggiero SL, Dodson TB, Assael LA, Landesberg R, Marx RE, Mehrotra B; Task Force on Bisphosphonate-Related Osteonecrosis of the Jaws, American Association of Oral and Maxillofacial Surgeons. American Association of Oral and Maxillofacial Surgeons position paper on bisphosphonate-related osteonecrosis of the jaw - 2009 update. Aust Endod J. 2009;35(3):119-30.

9. Marx RE, Cillo JE Jr, Ulloa JJ. Oral bisphosphonate-induced osteonecrosis: risk factors, prediction of risk using serum CTX testing, prevention, and treatment. J Oral Maxillofac Surg. 2007;65:2397-410. 
10. Marx RE, Sawatari Y, Fortin M, Broumand V. Bisphosphonate-induced exposed bone (osteonecrosis/osteopetrosis) of the jaws: risk factors, recognition, prevention, and treatment. J Oral Maxillofac Surg. 2005;63:1567-75.

11. Petcu EB, Ivanovski S, Wright RG, Slevin M, Miroiu RI, Brinzaniuc K. Bisphosphonate-related osteonecrosis of jaw (BRONJ): an anti-angiogenic side-effect? Diagn Pathol. 2012;7:78.

12. Sharma D, Ivanovski S, Slevin M, Hamlet S, Pop TS, Brinzaniuc $\mathrm{K}$, et al. Bisphosphonate related osteonecrosis of jaw (BRONJ): diagnostic criteria and possible pathogenic mechanisms of an unexpected antiangiogenic side effect. Vasc Cell. 2013;5(1):1

13. Rasmusson L, Abtahi J. Bisphosphonate associated osteonecrosis of the jaw: an update on pathophysiology, risk factors, and treatment. Int J Dent. 2014:471035.

14. Ercoşkun H, Uğuz Ş, Kuralan M. Conjugated linoleic acid. Gida Mühendisliği Dergisi 2005;(19):42-6.

15. Samson FP, Patrick AT, Fabunmi TE, Yahaya MF, Madu J, He W, et al. Oleic Acid, Cholesterol, and Linoleic Acid as Angiogenesis Initiators. ACS Omega. 2020;5:20575- 85.

16. Camacho-Alonso F, López-Jornet P, Vicente-Hernández A. Short-term effect of zoledronic acid upon fracture resistance of the mandibular condyle and femoral head in an animal model. Med Oral Patol Oral Cir Bucal. 2013;18:421-6.

17. Kün-Darbois J-D, Libouban H, Mabilleau G, Pascaretti-Grizon F, Chappard D. Bone Mineralization and Vascularization in Bisphosphonate-Related Osteonecrosis of the Jaw: An ExperimentalStudy in the Rat. Clin Oral Investig. 2018;22(9):2997-3006.

18. Geddes RI, Hayashi K, Bongers Q, Wehber M, Anderson IM, Jansen AD, et al. Conjugated Linoleic Acid Administration Induces Amnesia in Male Sprague Dawley Rats and Exacerbates Recovery from Functional Deficits Induced by a Controlled Cortical Impact Injury. PLoSOne. 2017;12(1):e0169494.

19. Dodson TB. Intravenous bisphosphonate therapy and bisphosphonate-related osteonecrosis of the jaws. J Oral Maxillofac Surg. 2009;67(5):44-52.

20. Barba-Recreo P, Del Castillo Pardo de Vera JL, García-Arranz M, Yébenes L, Burgueño M. Zoledronic acid - related osteonecrosis of the jaws. Experimental model with dental extractions in rats. J Craniomaxillofac Surg. 2014;42(6):744-50.

21. Hoff AO, Toth BB, Altundag K, Johnson MM, Warneke $\mathrm{CL}, \mathrm{Hu} \mathrm{M}$, et al. Frequency and risk factors associated with osteonecrosis of the jaw in cancer patients treated with intravenous bisphosphonates. J Bone Miner Res. 2008;23(6):826-36.

22. Ficarra G, Beninati F. Bisphosphonte-related osteonecrosis of the jaws: the point of view of the oral pathologist. Clin Cases Miner Bone Metab. 2007;4:53-7.

23. Lametschwandtner A, Lametschwandtner U, Weiger T. Scanning electron microscopy of vascular corrosion casts--te- chnique and applications: updated review. Scanning Microsc. 1990;4(4):889-940; discussion 941.

24. Aharinejad S, Franz P, Firbas W, Fakhari M. Mandibular and molar vascularization in guinea pigs. Scanning electron microscopic study of corrosion casts. Anat Rec. 1990;228(4):471-7.

25. Yoshida S, Ohshima H, Kobayashi S. Vascularization of the enamel organ in developing molar teeth of rats - scanning electron microscope study of corrosion casts. Okajimas Folia Anat Jpn. 1989;66:99-112.

26. Tsukada H, Ishikawa H, Nakamura S, Yoshida S. Developmental changes of the vasculature in the periodontal ligament of rat molars: a scanning electron microscopic study of microcorrosion casts. J Periodontal Res. 2000;35:201-7.

27. Aghaloo TL, Kang B, Sung EC, Shoff M, Ronconi M, Gotcher JE, et al. Periodontal disease and bisphosphonates induce osteonecrosis of the jaws in the rat. J Bone Miner Res. 2011;26:1871-82.

28. Chung WO, Dommisch H, Yin L, Dale BA. Expression of defensins in gingiva and their role in periodontal health and disease. Curr Pharm Des. 2007;13:3073-83.

29. Slade GD, Beck JD. Plausibility of periodontal disease estimates from NHANES III. J Public Health Dent. 1999;59:67-72.

30. Samson FP, Fabunmi TE, Patrick AT, Jee D, Gutsaeva DR, Jahng WJ. Fatty Acid Composition and Stoichiometry Determine the Angiogenesis Microenvironment. ACS Omega 2021.https:/ / dx.doi.org/10.1021/acsomega.1c00196

31. Kang JX, Liu A. The role of the tissue omega-6/omega-3 fatty acid ratio in regulating tumor angiogenesis. Cancer Metastasis Rev. 2013;32:201-10.

32. Wang QY, Dai J, Kuang B, Zhang J, Yu SB, Duan YZ, Wang MQ. Osteochondral angiogenesis in rat mandibular condyles with osteoarthritis-like changes. Arch Oral Biol. 2012;57(6):620-9.

33. Widyastuti, Rubianto M, Soetjipto. Induction of Angiogenesis Process in Mandible Using Anadara granosa Shell Graft (Experimental Laboratory Study on Rattus norvegicus). In: IOP Conference Series: Earth and Environmental Science. IOP Publishing 2018;217:012033.

34. Luthfi M, Juliastuti WS, Risky YA, Wijayanti EH, Rachmawati AE, Asyhari NPO. Expression of fibroblast cells after extraction of wistar rat teeth after topical application of okra fruit (Abelmoschus esculentus) gel. Infect Dis Rep. 2020;12(1):8726.

35. Rowe NM, Mehara BJ, Luchs JS, Dudziak ME, Steinbrech DS, Illei PB, et al. Angiogenesis during mandibular distraction osteogenesis. Ann Plast Surg. 1999;42:470-5. 